\title{
Study on the $\mathrm{Hg}$ content of coal in Dahebian coal mine
}

\author{
Yonghua Ji ${ }^{1, a}$, Bingke Qin ${ }^{1,2, b}$, Peng Chen ${ }^{1, c}$, Shuai Li ${ }^{1, d}$ \\ ${ }^{1}$ School of Chemistry and materials Engineering, Liupanshui Normal University, Liupanshui, China \\ ${ }^{2}$ College of Materials and Metallurgy, Guizhou University, Guiyang, China \\ ahaizhigong@126.com, bqinbingke@126.com, `kr2012@126.com, djyh129217@163.com.
}

\begin{abstract}
Keywords: Hg; coal; Nitrification; Atomic fluorescence spectrophotometer
Abstract. This study first analyzed the phase composition of Dahebian coal mine by XRD, then do the experiment of screening, float and sink test, following the $\mathrm{Hg}$ content of coal was determined by atomic fluorescence spectrophotometer, and the regularities of distribution of $\mathrm{Hg}$ was studied. The results showed that the $\mathrm{Hg}$ content of the coal increased with the ash, density increasing, which indicated that $\mathrm{Hg}$ had a certain inorganic affinity. There is a significant correlation between $\mathrm{Hg}$ content and average density, when the density exceeded $1.8 \mathrm{~g} / \mathrm{cm}^{3}$, the maximum $\mathrm{Hg}$ content reached to be $0.97 \mathrm{ppm}$. At the same time the maximum sulfur and ash also measured respectively, it is $0.46 \%$ and $56.32 \%$.
\end{abstract}

\section{Introduction}

There are two sources of $\mathrm{Hg}$ in atmospheric environment, one is natural source, and the other is artificial source. Natural sources include wind-blown sand, raise dust, volcanic activity, mineral release, forest fire, biological causes and so on. Artificial sources include mining, smelting, processing, transportation, waste incineration, energy utilization and so on. Among them, $\mathrm{Hg}$ in the atmosphere is a large part of anthropogenic activities, and the $\mathrm{Hg}$ released by coal combustion accounts for a large portion of $\mathrm{Hg}$ released by human activities [1-3].

China is the world's first coal power energy structure, coal accounted for more than $60 \%$, in the foreseeable future decades, coal dominated energy structure will not change in China, coal will continue to be a major component of China's primary energy supply in the future [4]. Moreover, China's coal combustion technology is generally backward, low proportion of coal sorting rate, most of the steam coal without sorting. The mercury content of coal in China is extremely uneven, mainly concentrated in the range of $0.1 \sim 0.4 \mu \mathrm{g} / \mathrm{g}$. The $\mathrm{Hg}$ content of coal is relatively rich, and the $\mathrm{Hg}$ content in different plants is very different. Therefore, the $\mathrm{Hg}$ content of coal formed by different coal forming plants is different,the highest $\mathrm{Hg}$ content in Chinese coal is mainly distributed in Guizhou. In addition, Guizhou is China's major coal producing province, in recent years, Guizhou's annual coal combustion up to 8 million tons, and did not take any measures or clean flue gas emissions, therefore, human activities in Guizhou province to quantity of atmospheric $\mathrm{Hg}$ emissions is also very alarming, accounting for about $12 \%$ of global anthropogenic emissions of $\mathrm{Hg}$.

The consensus of researchers at home and abroad is that pyrite of coal is the main carrier of $\mathrm{Hg}$, especially in epigenetic pyrite, and the distribution of $\mathrm{Hg}$ in pyrite is uneven. In addition, the sulfide or selenide minerals of coal (such as sphalerite) may also contain $\mathrm{Hg}[5,6]$.

In this paper, the determination of $\mathrm{Hg}$ content in coal by using advanced instruments, the distribution mechanism of $\mathrm{Hg}$ in Liupanshui area Dahebian coal mine was researched through screening and float-sink test; it can provide theoretical basis and technical support for resource utilization of high $\mathrm{Hg}$ content coal.

\section{Experiment}

The coal samples collected from Liupanshui Dahebian coal mine. First, the coal samples were dried to air-dried state, and then according to the grain size> 50, $50 \sim 25,25 \sim 13,13 \sim 6,6 \sim 3,3 \sim 1,1 \sim 0.5$, $<0.5 \mathrm{~mm}$ screened into eight parts. Next, the coal samples of each particle size were crushed, divided, 
sample prepared, and screening into $-0.2 \mathrm{~mm}$ and $-0.074 \mathrm{~mm}$. The coal samples of each particle size are measured of moisture content, ash content and total sulfur.

When did float-sink test of selected coal samples, the heavy-fluid is mixed liquor of zinc chloride and water. The coal samples divided into seven density level according to $<1.3,1.3 \sim 1.4,1.4 \sim 1.5$, $1.5 \sim 1.6,1.6 \sim 1.7,1.7 \sim 1.8,>1.8 \mathrm{~g} / \mathrm{cm}^{3}$. Each of the density grade coal samples obtained after the float-sink test was crushed, divided, sample prepared, and screening into $-0.2 \mathrm{~mm}$ and $-0.074 \mathrm{~mm}$, Then the moisture, ash, total sulfur and $\mathrm{Hg}$ content of each density class of coal samples were determined.

Accurately weighing coal samples which is below 200 mesh of each size grade, density level $0.1 \pm$ $0.0001 \mathrm{~g}$, putted into the group which has been numbered digestion bottle, added $50 \%$ of aqua regia $10 \mathrm{ml}$, shock heated $1 \mathrm{~h}$ in the $95{ }^{\circ} \mathrm{C}$ thermostat water bath. After added $50 \%$ of aqua regia $20 \mathrm{ml}, 1 \mathrm{~h}$ after removed the bottle to stand still cooling down to room temperature, then added $1 \%$ of potassium permanganate solution $40 \mathrm{ml}$, putted back to $95^{\circ} \mathrm{C}$ thermostat water bath, heated to digestion until the solution was completely clarified, the solution was determined by filtration and constant volume. The $\mathrm{Hg}$ content was determined by AFS-9700 dual channel atomic fluorescence spectrometer.

\section{Results and discussion}

Raw coal XRD analysis. Figure 1 is the test pattern of the raw coal by XRD. According to the patterns, the scanning step was 0.05 , scanning angle range was $5^{\circ} \sim 65^{\circ}$. The analysis of the material phase showed that the raw coal in Dahebian coal mine contained quartz, kaolin, common pyrite, and so on minerals.

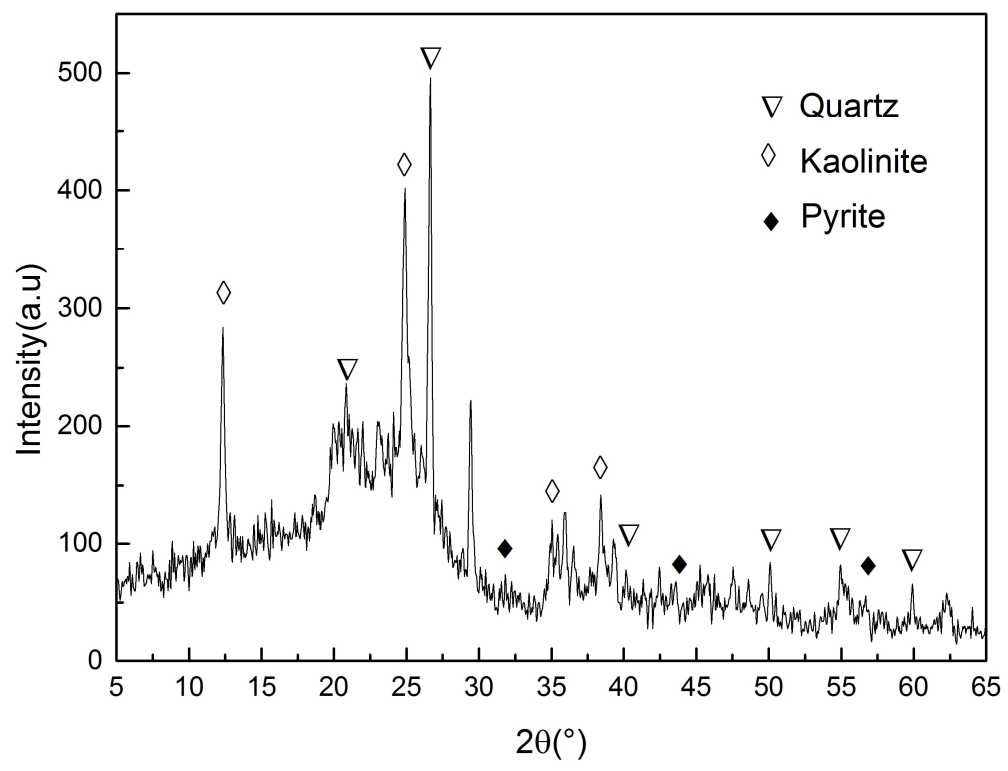

Fig.1 XRD patterns of raw coal in Dahebian coal mine

Analysis of $\mathrm{Hg}$ content, ash content and total sulfur in different granular coal. Table 1 is the test results of ash, sulfur and $\mathrm{Hg}$ content of different grades raw coal in Dahebian coal mine, from the test data we can see the $\mathrm{Hg}$ content increased with the increase of ash in coal on the whole. When the size of coal is above $50 \mathrm{~mm}$, the maximum $\mathrm{Hg}$ content is $0.96 \mathrm{ppm}$, at the same time the ash and total sulfur also reached the maximum, respectively is $39.03 \%$ and $0.43 \%$. In different size grades of raw coal, $\mathrm{Hg}$ content and ash showed a certain correlation, which indicated that $\mathrm{Hg}$ had a certain inorganic affinity.

Analysis of $\mathrm{Hg}$ content, Ash and total sulfur in different density level coal. The results of ash, sulfur and $\mathrm{Hg}$ content of the density of coal in Dahebian coal mine are shown in Table.2. From the test datas can be seen, with the increase in the density of raw coal, ash, total sulfur and $\mathrm{Hg}$ content has also increased, when the density is over $1.8 \mathrm{~g} / \mathrm{cm}^{3}$, the maximum $\mathrm{Hg}$ content was obtained $0.97 \mathrm{ppm}$. At the 
same time the total sulfur and ash also measured the maximum, respectively is $0.46 \%$ and $56.32 \%$. ash and $\mathrm{Hg}$ content showed a certain correlation.

Table1. Ash content, total sulfur and $\mathrm{Hg}$ content in different size grades in Dahebian coal mine

\begin{tabular}{cccc}
\hline Size grade $(\mathrm{mm})$ & ash $\mathrm{A}_{\mathrm{d}}(\%)$ & sulfur $\mathrm{S}_{\mathrm{t}, \text { ad }}(\%)$ & Hg content $(\mathrm{ppm})$ \\
\hline+50 & 39.03 & 0.43 & 0.96 \\
$50 \sim 25$ & 30.57 & 0.38 & 0.83 \\
$25 \sim 13$ & 29.77 & 0.28 & 0.76 \\
$13 \sim 6$ & 27.30 & 0.21 & 0.62 \\
$6 \sim 3$ & 32.78 & 0.27 & 0.55 \\
$3 \sim 1$ & 24.36 & 0.26 & 0.51 \\
$1 \sim 0.5$ & 25.72 & 0.26 & 0.43 \\
-0.5 & 28.12 & 0.27 & 0.45 \\
\hline
\end{tabular}

Table 2. Test result of ash, sulfur and $\mathrm{Hg}$ content in each density level

\begin{tabular}{cccc}
\hline Density $\left({\left.\mathrm{g} \cdot \mathrm{cm}^{-3}\right)}^{-3}\right.$ & Ash $\mathrm{A}_{\mathrm{d}}(\%)$ & Sulfur $_{\mathrm{t}, \text { ad }}(\%)$ & Hg content $(\mathrm{ppm})$ \\
\hline-1.3 & 6.16 & 0.22 & 0.44 \\
$1.3 \sim 1.4$ & 16.91 & 0.28 & 0.53 \\
$1.4 \sim 1.5$ & 20.74 & 0.30 & 0.61 \\
$1.5 \sim 1.6$ & 26.24 & 0.31 & 0.72 \\
$1.6 \sim 1.7$ & 25.80 & 0.35 & 0.81 \\
$1.7 \sim 1.8$ & 48.05 & 0.40 & 0.85 \\
+1.8 & 56.32 & 0.46 & 0.97 \\
\hline
\end{tabular}

Fig. 2 showed the relationship between the average density and $\mathrm{Hg}$ content of Dahebian coal. It can be seen from the figure that there is a significant correlation between $\mathrm{Hg}$ content and average density, the fitting model value of $\mathrm{R}^{2}$ was 0.9966 , and between fitting model and actual data shown a good correlation.

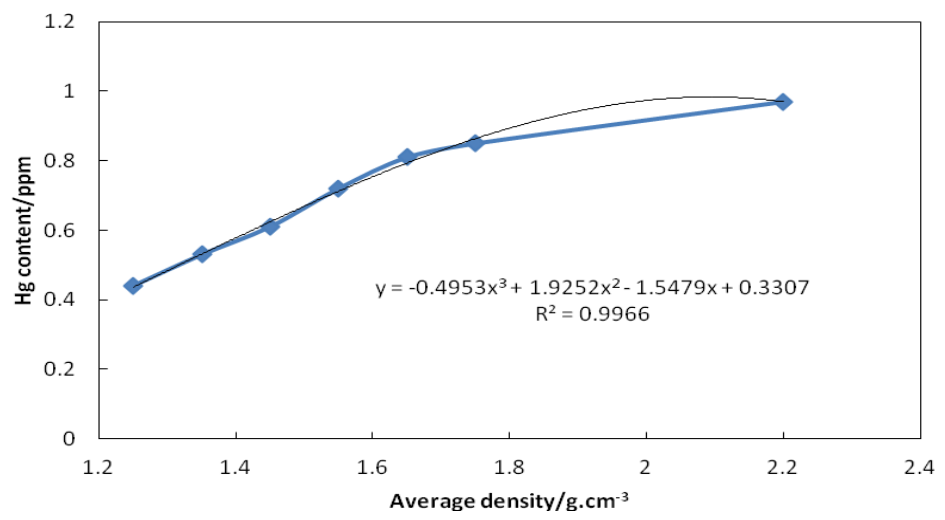

Fig. 2 The relationship between the average density and $\mathrm{Hg}$ content of the coal

Comprehensive analysis the test results of $\mathrm{Hg}$ content, ash and sulfur of different size grade and different density in Dahebian coal mine, the $\mathrm{Hg}$ content increased with the increase of ash in coal on the whole, with the increase of density of raw coal, ash, total sulfur and $\mathrm{Hg}$ content has also increased. there is a significant correlation between $\mathrm{Hg}$ content and average density. 


\section{Conclusions}

Based on the analysis of XRD spectra of raw coal in Dahebian coal mine, the raw coal contained quartz, common pyrite, kaolin and so on minerals. As a whole, the Hg content increases with the ash increasing, which indicates that $\mathrm{Hg}$ has a certain inorganic affinity. The $\mathrm{Hg}$ content of the coal is proportional to the density and size of Dahebian coal. When the size grade of raw coal is above 50mm, the maximum ash and sulfur respectively is $39.03 \%$ and $0.43 \%$, and the maximum $\mathrm{Hg}$ content is $0.96 \mathrm{ppm}$. There is a significant correlation between $\mathrm{Hg}$ content and average density, when the density is greater than $1.8 \mathrm{~g} / \mathrm{cm}^{3}$, the maximum mercury content is $0.97 \mathrm{ppm}$. At the same time the sulfur and ash also measured the maximum, respectively is $0.46 \%$ and $56.32 \%$.

\section{Acknowledgements}

This work was financially supported by the Guizhou provincial science and technology department joint fund (Qiankehe LKLS [2013] 18); Guizhou provincial department of education fund (Qianjiaohe Talent team zi [2015] 69); Key Supported Discipline of Guizhou Provence(Qian Xuewei He Zi ZDXK[2016]24);Guizhou provincial department of education foundation ([2014] 46).

\section{References}

[1] Junying Zhang, Deyi Ren, Dewei Xu, et al: Chinese Journal of Environmental Engineering Vol(1993), P:101-105. In Chinese.

[2] D.J.Swaine: Coal PreP Vol19(1998),P:177 193.

[3] Liugen Zheng,Guijian Liu, Cuicui Qi, et al:Journal of University of Science and Technology of China Vol(2007), P:953-963. In Chinese.

[4] Xiaohan Zhang, Niven Winchester, Xiliang Zhang, et al: Energy Policy Vol.110 (2017), P: 644-652.

[5] Wei Li, Hongfu Liu, Xiaoxia Song: International Journal of Coal Geology Vol. 144-145 (2015), P: $138-152$.

[6] Xu Ping, Zhang Bi, Zeng Xiaobo, et al: International Journal of Coal Geology Vol. 170 (2017), P: 14-18. 